Document downloaded from:

http://hdl.handle.net/10251/140196

This paper must be cited as:

Ramirez Hoyos, P.; Cervera Montesinos, J.; Ali, M.; Ensinger, W.; Mafé, S. (2014). Logic Functions with Stimuli-Responsive Single Nanopores. ChemElectroChem. 1(4):698-705. https://doi.org/10.1002/celc.201300255

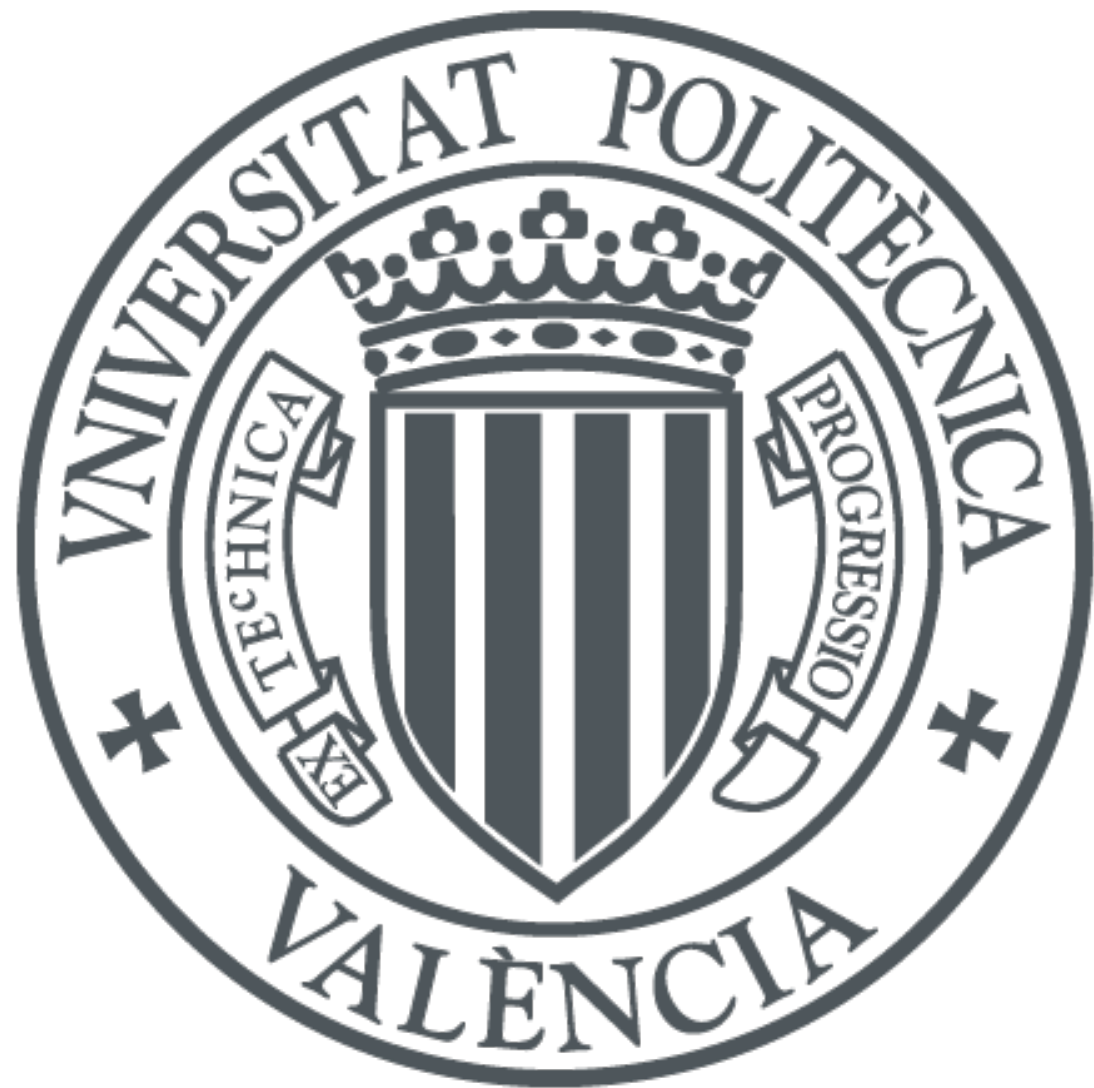

The final publication is available at

https://doi.org/10.1002/celc.201300255

Copyright John Wiley \& Sons

Additional Information

"This is the peer reviewed version of the following article: Logic Functions with StimuliResponsive Single Nanopores, which has been published in final form at https://doi.org/10.1002/celc.201300255. This article may be used for non-commercial purposes in accordance with Wiley Terms and Conditions for Self-Archiving." 


\title{
CONCEPT
}

\section{Logic functions with stimuli-responsive single nanopores}

\author{
Patricio Ramirez, ${ }^{[\mathrm{a}]}$ Javier Cervera, ${ }^{[\mathrm{b}]}$ Mubarak Ali, ${ }^{[\mathrm{c}] \mathrm{d}]}$ Wolfgang \\ Ensinger, ${ }^{[c]}$ and Salvador Mafe ${ }^{[b], *}$
}

We present the concept of logic functions based on a single stimuli-responsive nanopore and analyze its potential for electrochemical transducers and actuators. The responsive molecules at the surface of the polymeric nanopore immersed in an electrolyte solution are sensitive to thermal, chemical, electrical, and optical stimuli, which are the input signals required to tune externally the conductance of the nanopore (the logical output). A single nanostructure can be operated as a resistor or as a diode with a broad range of rectifying properties, allowing logical information processing schemes useful for $\mathrm{pH}$ and temperature sensors, electro-optical detectors, and electrochemical actuators and transducers. Some of the limitations to be addressed in practical applications are also cited.

\author{
[a] Prof. Dr. P. Ramirez \\ Departament. de Física Aplicada, \\ Universitat Politécnica de València, \\ E-46022 València, Spain \\ [b] Dr. J. Cervera, Prof. Dr. S. Mafe \\ Departament de Física de la Terra i Termodinàmica \\ Universitat de València \\ E-46100 Burjassot, Spain \\ E-mail: smafe@uv.es \\ [c] Dr. M. Ali, Prof. Dr. W. Ensinger \\ Department of Material- and Geo-Sciences \\ Technische Universität Darmstadt \\ D-64287 Darmstadt, Germany \\ [d] Dr. M. Ali \\ Materials Research Department \\ GSI Helmholtzzentrum für Schwerionenforschung \\ D-64291, Darmstadt, Germany
}




\section{Introduction}

Nanofluidic devices such as pores, ${ }^{[1-9]}$ electrodes, ${ }^{[9,10]}$ and pipettes, ${ }^{[11]}$ together with the ion channels of biological membranes, ${ }^{[12-14]}$ make use of the interaction between the charges fixed at the pore surface and the mobile ions in solution to process weak chemical and electrical signals in a noisy environment. To design information processing methods with stimuliresponsive nanopores, a previous step is to identify the input/output signals available to implement the basic logic functions. We review here logical schemes based on signal transduction with a single polymeric pore and consider implementations of simple networks and multifunctional devices on the basis of the electrochemical characteristics demonstrated experimentally.

This concept article is timely because the control of pre-determined nanopore geometry and surface functionalization has recently become possible. ${ }^{[2-21]}$ We will consider the case of single-track polymeric nanopores, but the fundamental concepts could also be implemented with solid-state pores, ${ }^{[21,22]}$ ion channels, ${ }^{[12,13]}$ and membranes. ${ }^{[3,4,23-26]}$ Logic functions can facilitate managing procedures in electrochemical sensing, amplifying signals in the liquid state, and triggering the controlled release of drugs using nanopores.

\section{Nanopore input/output signals}

The experimental procedures currently available permit a variety of shapes (cylindrical, conical, double conical, concave pores with bullet-like tips, and convex pores with trumpetlike tips $)^{[7,18-21,32-34]}$ and also an efficient control over surface chemistry..$^{[5,16,18,28-41]}$ To some extent, the biochemical diversity and functions of the ion channels inserted in the cell membranes can be mimicked by nanostructures based on asymmetric unipolar pores, bipolar diodes and transistors composed by regions of different charge juxtaposed in series, and nanofluidic diodes with amphoteric chains on the pore surface. ${ }^{[16,30,33,42]}$ Not only electrical 
${ }^{[16,37,41,43]}$ but also chemical, thermal, and optical interactions ${ }^{[30,39,44-48]}$ can be exploited. Table 1 shows some electrochemical effects used to tune externally the nanopore conductance that are well understood on the basis of simple theoretical approaches. ${ }^{[7,16,18,30,48-52]}$ Previous theoretical and experimental logical schemes at the nanoscale are based on molecular devices and self-assembled monolayers, ${ }^{[53]}$ nanonoparticle arrays, ${ }^{[54]}$ enzyme-based ${ }^{[55]}$ and DNA ${ }^{[56]}$ biomolecular systems.

\section{Implementing logic functions}

\section{Solution $p H$ and thermal input signals}

Biological ion channels with $\mathrm{pH}$-dependent fixed charges are known to be responsible for information processing in cell membranes. ${ }^{[12]}$ Track-etched, single conical nanopores modified with a monolayer of polyprotic acid chains exhibit three levels of conductance that can be modulated by the solution $p H$, allowing a multilevel response. ${ }^{[37]}$ Figure 1 shows a logical scheme where binary (AND) and multivalued functions are implemented using chemical $(p H)$ and electrical (voltage $V$ ) stimuli. The multivalued function of Figure 1 considers the product of the two input signals, assigning an output " 0 " when at least one of the signals is zero, an output" 1 " when both signals are one, and an output "2" in those cases where the product is equal to or greater than two.

It is also possible to combine the $p H$ and temperature effects by integrating thermallyresponsive polymer brushes into nanopores. ${ }^{[44-47,57]}$ The swelling/shrinking of the brushes caused by changes in the solution $p H$ and temperature allow external tuning of the conductance. ${ }^{[44,45]}$ Other experimental options include using the nanopore blocking by a charged macromolecule in solution ${ }^{[58]}$ and the adsorption of divalent cations on the negative surface charges giving a reversal in the nanopore surface charge. ${ }^{[59]}$ Although the logics " 0 " and " 1 " are only approximately defined because of the moderate rectification characteristics 
usually obtained, the rectification can be enhanced further by controlling the pore shape and charge distribution. ${ }^{[7,20,32-35,42,50,60-62]}$

Some experimental limitations should be cited. In addition to the irreversibility phenomena and aging of the nanostructures, ${ }^{[44,46,48]}$ the time response could also be an issue for polymeric pores. ${ }^{[37]}$ To achieve an efficient time modulation, the external tuning should involve pulses with time periods larger than the typical pore relaxation time characteristic of the nanopore. While, fast response times might be anticipated because of the nanoscale radial diffusion, ${ }^{[8]}$ the fact is that mass transfer could still be slow over the microscale pore length. An upper bound (because of the effect of the external electric field) for the response is the diffusion time $\tau=L^{2} / D_{\mathrm{i}}$, where $L$ is the length of the pore and $D_{\mathrm{i}}=10^{-10}-10^{-9} \mathrm{~m}^{2} / \mathrm{s}$ is the ionic diffusivity. This time is of the order of $1 \mathrm{~s}$ for a nanopore thickness $L=10 \mu \mathrm{m}$ but it could be decreased by several orders of magnitude in the case of biological ion channels ${ }^{[12-14]}$ and solid-state nanopores ${ }^{[21,22]}$ fabricated on silicon oxide, ceramics, and glass supports because $L$ $=10 \mathrm{~nm}$ in these cases and small chip integration is feasible. However, the effective operating time could still be significantly higher than expected because of the external connections and the fact that the system has both electronic and ionic characteristics. ${ }^{[8,31,63]}$ The use of electrical rather than chemical gating may allow fast and long-lasting devices.

\section{Electrical gating and field-effect mechanisms}

Theoretical and experimental studies have shown that the conductance can also be controlled by gating mechanisms similar to those characteristic of field-effect transistors. In particular, a dielectric film layer can be deposited on a metallic surface inside the pore. When an electrolyte solution is in contact with this insulating layer, different ionic conductance levels can be externally modulated by a gate potential applied directly to the metallic layer covering the pore. ${ }^{[21,22,41,43]}$ All inputs and outputs are electrical here, which facilitates the integration of 
single units and permits fast responses compared with the cases of thermal and chemical signals.

However, the gating effects are moderate and only partly understood. ${ }^{[21,22,43,64-67]}$ The efficiency of the conductance modulation depends on the effective gate potential at the insulating surface in contact with the inner electrolyte solution, which is much lower than the applied gate potential at the metallic surface ${ }^{[41]}$ Moreover, the gate insulating layer may show a non-zero surface charge (and then an additional potential shift) that may affect the conductance gating. Significant progress has been achieved with field-effect reconfigurable nanofluidic diodes, ${ }^{[64-67]}$ which suggests applications in gate-controlled electrostatic sorting of charged biomolecules in solution. In addition, reconfiguration could be easily implemented using electrical pulses instead of chemical signals in continuous operation.

\section{Optical signals}

Information processing with light-based systems use chemical signals as inputs and optical (e.g., fluorescence) signals as outputs. ${ }^{[56]}$ The inside surface of glass nanopore electrodes can be modified with optically active moieties to impart photochemical control of transport. ${ }^{[68]}$ Optical gating has also been demonstrated in polymeric nanopores ${ }^{[48,69,70-72]}$ decorated with a monolayer of photo-labile hydrophobic molecules that can be removed by irradiation, leading to hydrophilic groups. ${ }^{[48]}$ For those applications where the reset function is required, quasireversible gating can be achieved. ${ }^{[68,70,71]}$ Applications have been suggested concerning photoinduced control of mass-delivery, sensing, and catalysis. ${ }^{[48,69-72]}$ Stability and responsive switching have been demonstrated during several cycles for dual-driven systems. ${ }^{[70,71]}$

\section{Logical networks and multifunctional single nanopores}

Logical networks can also be designed using a three-compartment electrochemical cell with two nanopores. Integration of several pores in a series arrangement can allow multiple sensing 
and actuating. Figure 2 suggests an experimental realisation for the enabled $O R(E n O R)$ function where a simple binary output (current) can be obtained from different combinations of chemical, thermal, and electrical inputs. The currents are estimated from the individual pore conductances. Note that an optical input can also be used instead of the thermal input if reversible changes in the optically tuned conductance are realized. ${ }^{[68,70,71]}$

Figure 2 shows that simple networks can be operated in electrochemical cells at the price of increasing the spatial dimensions. A more challenging task is to integrate the ionic circuits on microchips ${ }^{[27-29]}$ to achieve full functionality. Alternatively, a single nanostructure can provide different logical functionalities without the necessity of concatenating many single units, as it has recently been reported for the cases of a DNA sandwich structure containing ATP aptamers ${ }^{[73]}$ and one molecule incorporating several photochromes (photoswitchable bistable chromophores). ${ }^{[74]}$ Figure 3 shows a nanopore ${ }^{[75,76]}$ that can provide three different functionalities difficult to implement in practice (note that the INH function should give logic " 0 " for all cases except for one particular combination of inputs " 0 " and "1") without the necessity of concatenating several units. This fact should permit multiple sensing and actuating in practical applications with a significant simplification of the circuitry. ${ }^{[76-78]}$

\section{Conclusion}

Logical schemes implemented on a single nanopore that can respond to thermal, chemical, electrical, and optical stimuli may be exploited in transducers and actuators based on electrochemical signals. The use of nanopore arrays in energy storage technology is also promising $^{[26]}$ and the introduction of basic logic functions can facilitate managing procedures. We have emphasized here the fundamental concepts rather than the integration of single elements in approximately defined architectures. The electrochemical signals can be provided 
by the external electrodes and by recirculating small volumes of fresh solutions. ${ }^{[7,27-29,79-86]}$ Other practical issues not considered here are the stability and durability after several cycles, ${ }^{[19,71]}$ the significant noise-to-signal ratio, ${ }^{[8,63]}$ and the mass transport limitations that may appear at high frequency pulses. ${ }^{[63,79,85]}$ In this context, the cigar-shaped pore of Figure 3 permits a convenient external reconfiguration ${ }^{[75,76]}$ because of the direct experimental access to the functionalized pore mouths, providing multifunctional responses with a single nanostructure. Biological ion channels could also be used, ${ }^{[12-14,84]}$ especially for the conversion between ionic and electronic currents at the biological-electronic interface. ${ }^{[81,87]}$

Although, it should be recognized that some techniques employed in fundamental research may be difficult to translate into portable industrial designs, the electrochemical concepts discussed here are general and can be implemented in other pore-based ionic current devices with macroscopic regions..$^{[7,8,28,29,31,77,78,81]}$ In particular, chemical logic gates based on polyelectrolyte diodes and bipolar junctions integrated on ionic circuits have been demonstrated. ${ }^{[28,77]}$ Although organic materials offer a wide range of chemical functionalizations, ${ }^{[2,27,70]}$ other practical realizations should also be possible with solid-state nanopores because of the possibility to fabricate different hetero-structures with the available pattern transfer processes. ${ }^{[21,22,65,81-83]}$

\section{Acknowledgements}

P. R., J. C., and S. M. acknowledge the financial support from the Generalitat Valenciana (Project Prometeo/GV/0069), the Ministry of Economy and Competitiveness of Spain, (Materials Program, project No. MAT2012-32084), and FEDER. M. A. and W. E. gratefully acknowledge financial support by the Beilstein-Institut, Frankfurt/Main, Germany, within the research collaboration NanoBiC. 
Keywords: nanopore, logic functions, sensors, signal transduction, surface chemistry

\section{Table of contents}
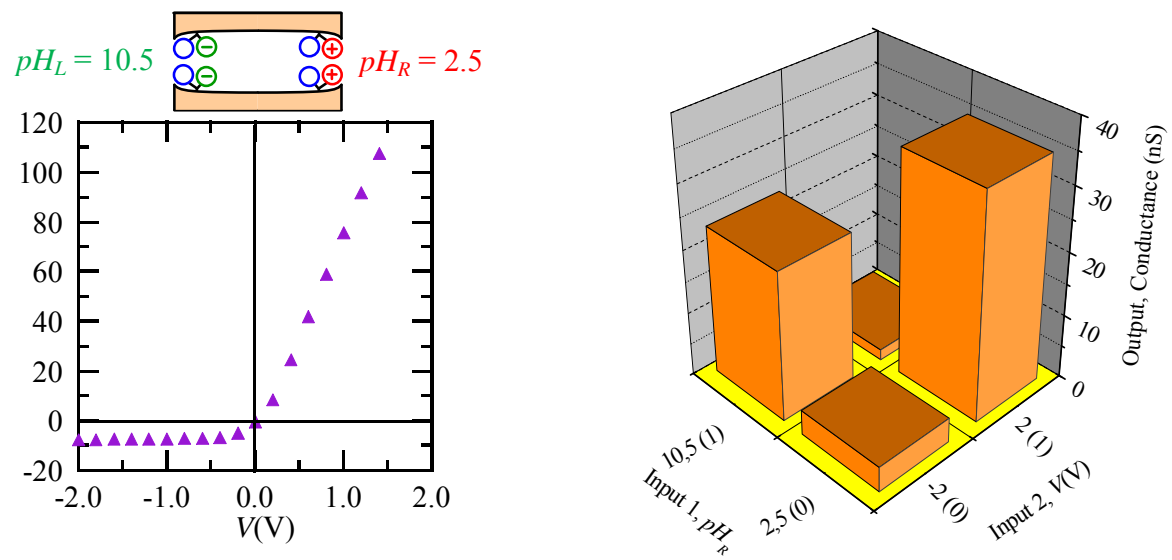

Electrochemical transducers based on a single stimuli-responsive polymeric nanopore can support a complete set of logic functions. Thermal, chemical, electrical, and optical stimuli are the input signals required to tune externally the pore conductance (the logical output). 
[1] Z. Siwy, Y. Gu, H. A. Spohr, D. Baur, A. Wolf-Reber, R. Spohr, P. Apel, Y. E. Korchev, Europhys. Lett. 2002, 60, 349-355.

[2] C. C. Harrell, Z. S. Siwy, C. R. Martin, Small 2006, 2, 194-198.

[3] J. R. Ku, S. M. Lai, N. Ileri, P. Ramirez, S. Mafe, P. Stroeve, J. Phys. Chem. C 2007, 111, 2965-2973.

[4] K. Healy, B. Schiedt, A. P. Morrison, Nanomedicine 2007, 2, 875-897.

[5] M. Ali, B. Yameen, R. Neumann, W. Ensinger, W. Knoll, O. Azzaroni, J. Am. Chem. Soc. 2008, 130, 16351-16357.

[6] R. W. Murray, Chem. Rev. 2008, 108, 2688-2720.

[7] D. Hlushkou, J. M. Perry, S. C. Jacobson, U. Tallarek, Anal. Chem. 2012, 84, 267-274.

[8] J. S. Ellis, G. Herzog, P. Gavin, Nano Comm. Networks 2011, 2, 62-73.

[9] K. Lebedev, S. Mafe, P. Stroeve, J. Phys. Chem. B 2005, 109, 14523-14528.

[10] Y. H. Zhang, B. Zhang, H. S. White, J. Phys. Chem. B 2006, 110, 1768-1774.

[11] S. Umehara, M. Karhanek, R. W. Davis, N. Pourmand, Proc. Natl. Acad. Sci. U.S.A. 2009, 106, 4611-4616.

[12] B. Hille, Ion channels of excitable membranes, 3rd ed., Sinauer Associates, Sunderland, 1992.

[13] A. Alcaraz, P. Ramirez, E. Garcia-Gimenez, M. L. Lopez, A. Andrio, V. M. Aguilella, J. Phys. Chem. B 2006, 110, 21205-21209.

[14] C. Verdiá-Báguena, M. Queralt-Martín, V. M. Aguilella, A. Alcaraz, J. Phys. Chem. C. 2012, 116, 6537-6542.

[15] M. Ali, B. Schiedt, K. Healy, R. Neumann, W. Ensinger, Nanotechnology 2008, 19, 085713.

[16] M. Ali, P. Ramirez, S. Mafe, R. Neumann, W. Ensinger, ACS Nano 2009, 3, 603-608. 
[17] C. C. Harrell, P. Kohli, Z. Siwy, C. R. Martin, J. Am. Chem. Soc. 2004, 126, 1564615647.

[18] P. Ramirez, P. Y. Apel, J. Cervera, S. Mafe, Nanotechnology 2008, 19, 315707.

[19] M. Ali, S. Nasir, P. Ramirez, J. Cervera, S. Mafe, W. Ensinger, J. Phys. Chem. C 2013, $117,18234-18242$.

[20] J. Cervera, P. Ramirez, S. Mafe, P. Stroeve, Electrochim. Acta 2011, 56, 4504-4511.

[21] R. Fan, M. Yue, R. Karnik, A. Majumdar, P. Yang, Phys. Rev. Lett. 2005, 95, 086607.

[22] R. Karnik, C. Duan, K. Castelino, H. Daiguji, A. Majumdar, Nano Lett. 2007, 7, 547551.

[23] Z. Siwy, L. Trofin, P. Kohli, L. A. Baker, C. Trautmann, C. R. Martin, J. Am. Chem. Soc. 2005, 127, 5000-5001.

[24] K.-Y. Chun, S. Mafe, P. Ramirez, P. Stroeve, Chem. Phys. Lett. 2006, 418, 561-564.

[25] M. Ali, M. N. Tahir, M. Z. Siwy, R. Neumann, W. Tremel, W. Ensinger, Anal. Chem. 2011, 83, 1673-1680.

[26] Y. Hou, R. Vidu, P. Stroeve, Ind. Eng. Chem. Res. 2011, 50, 8954-8964.

[27] G. Maglia, A. J. Heron, W. L. Hwang, M. A. Holden, E. Mikhailova, Q. Li, S. Cheley, H. Bayley, Nature Nanotech. 2009, 4, 437-440.

[28] J.-H. Han, K. B. Kim, H. C. Kim, T. D. Chung, Angew. Chem. Int. Ed. 2009, 48, 38303833.

[29] K. Tybrandt, K. C. Larsson, A. Richter-Dahlfors, M. Berggren, Proc. Nat. Acad. Sci. U.S.A. 2010, 107, 9929-9932.

[30] M. Ali, P. Ramirez, M. N. Tahir, S. Mafe, Z. Siwy, R. Neumann, W. Tremel, W. Ensinger, Nanoscale 2011, 3, 1894-1903.

[31] S. Senapati, S. Basuray, Z. Slouka, L.-J. Cheng, H.-C. Chang, Top. Curr. Chem. 2011, 304, 153-169. 
[32] P. Y. Apel, I. V. Blonskaya, S. N. Dmitriev, O. L. Orelovitch, A. Presz, B. A. Sartowska, Nanotechnology 2007, 18, 305302.

[33] E. B. Kalman, I. Vlassiouk, Z. Siwy, Adv. Mater. 2008, 20, 293-297.

[34] P. Y. Apel, I. V. Blonskaya, O. L. Orelovitch, P. Ramirez, B. A. Sartowska, Nanotechnology 2011, 22, 175302.

[35] P. Ramirez, V. Gomez, J. Cervera, B. Schiedt, S. Mafe, J. Chem. Phys. 2007, 126, 194703.

[36] F. Xia, W. Guo, Y. Mao, X. Hou, J. Xue, H. Xia, L. Wang, Y. Song, H. Ji, Q. Ouyang, Y. Wang, L. J. Jiang, J. Am. Chem. Soc. 2008, 130, 8345-8350.

[37] M. Ali, S. Mafe, P. Ramirez, R. Neumann, W. Ensinger, Langmuir 2009, 25, 11993 11997.

[38] M. Ali, S. Nasir, P. Ramirez, J. Cervera, S. Mafe, W. Ensinger, ACS Nano 2012, 6, $9247-$ 9257.

[39] X. Hou, W. Guo, F. Xia, F.-Q. Nie, H. Dong, Y. Tian, L. Wen, L. Wang, L. Cao, Y. Yang, J. Xue, Y. Song, Y. Wang, D. Liu, L. Jiang, J. Am. Chem. Soc. 2009, 131, 7800-7805.

[40] M. Ali, B. Yameen, J. Cervera, P. Ramirez, R. Neumann, W. Ensinger, W. Knoll, O. Azzaroni, J. Am. Chem. Soc. 2010, 132, 8338-8348.

[41] S. Mafe, J. A. Manzanares, P. Ramírez, J. Phys. Chem. C 2010, 114, 21287-21290.

[42] I. Vlassiouk, Z. A. Siwy, Nano Lett. 2007, 7, 552-556.

[43] E. B. Kalman, O. Sudre, I. Vlassiouk, Z. Siwy, Anal. Bioanal. Chem. 2009, 394, 413419.

[44] B. Yameen, M. Ali, R. Neumann, W. Ensinger, W. Knoll, O. Azzaroni, Small 2009, 5, 1287-1291.

[45] B. Yameen, M. Ali, R. Neumann, W. Ensinger, W. Knoll, O. Azzaroni, Nano Lett. 2009, 9, 2788-2793.

[46] X. Hou, F. Yang, L. Li, Y. Song, L. Jiang, D. Zhu, J. Am. Chem. Soc. 2010, 132, 1173611742 . 
[47] W. Guo, H. Xia, L. Cao, F. Xia, S. Wang, G. Zhang, Y. Song, Y. Wang, L. Jiang, D. Zhu, Adv. Funct. Mater. 2010, 20, 3561-3567.

[48] M. Ali, S. Nasir, P. Ramirez, I. Ahmed, Q. H. Nguyen, L. Fruk, S. Mafe, W. Ensinger, Adv. Funct. Mat. 2012, 22, 390-396.

[49] J. Cervera, A. Alcaraz, B. Schiedt, R. Neumann, P. Ramirez, J. Phys. Chem. C 2007, $111,12265-12273$.

[50] J. Cervera, B. Schiedt, R. Neumann, S. Mafe, P. Ramírez, J. Chem. Phys. 2006, 124, 104706.

[51] K. Kontturi, L. Murtomäki, J. A. Manzanares, Ionic Transport Processes, Oxford University Press, Oxford, 2008.

[52] J. Cervera, P. Ramirez, J. A. Manzanares, S. Mafe, Microfluid. Nanofluid. 2010, 9, 4153.

[53] J. A. Manzanares, J. Cervera, S. Mafe, J. Phys. Chem. C 2011, 115, 6980-6985.

[54] J. Cervera, S. Mafe, ChemPhysChem 2010, 11, 1654-1658.

[55] M. Pita, M. Krämer, J. Zhou, A. Poghossian, M. J. Schöning, V. M. Fernandez, E. Katz, ACS Nano 2008, 2, 2160-2166.

[56] F. Pu, J. Ren, X. Yang, X. Qu, Chem. Eur. J. 2011, 17, 9590-9594.

[57] L.-X. Zhang, S.-L. Cai, Y.-B. Zheng, X.-H. Cao, Y.-Q. Li, Adv. Funct. Mater. 2011, 21, 2103-2107.

[58] M. Aguilella-Arzo, J. Cervera, P. Ramírez, S. Mafe, Phys. Rev. E 2006, 73, 041914.

[59] T. Jimbo, A. Tanioka, P. Ramírez, S. Mafe, N. Minoura, J. Colloid Interface Sci. 2000, $225,447-454$.

[60] R. B. Schoch, J. Han, P. Renaud, Rev. Mod. Phys. 2008, 80, 839-883.

[61] L.-J. Cheng, L. J. Guo, ACS Nano 2009, 3, 575-584.

[62] P. Ramirez, H. J. Rapp, S. Mafe, B. Bauer, J. Electroanal. Chem. 1994, 375, 101-108.

[63] S. G. Lemay, ACS Nano 2009, 3, 775-779. 
[64] X. P. Gao, G. Zheng, C. M. Lieber, Nano Lett. 2010, 10, 547-552.

[65] W. Guan, R. Fan, M. A. Reed. Nat. Commun. 2011, 2, 506-512.

[66] Z. Jiang, D. Stein, Phys. Rev. E 2011, 83, 031203.

[67] N. Hu, Y. Ai, S. Qian, Sens. Actuators B 2012, 161, 1150-1167

[68] G. Wang, A. K. Bohaty, I. Zharov, H. S. White, J. Am. Chem. Soc. 2006, 128, 1355313558 .

[69] S. Nasir, P. Ramirez, M. Ali, I. Ahmed, L. Fruk, S. Mafe, W. Ensinger, J. Chem. Phys. 2013, 138, 034709.

[70] X. Hou, W. Guo, L. Jiang, Chem. Soc. Rev. 2011, 40, 2385-2401.

[71] L. Wen, Q. Liu, J. Ma, Y. Tian, C. Li, Z. Bo, L. Jiang, Adv. Mater. 2012, 24, 6193-6198.

[72] L. Wen, J. Ma, Y. Tian, J. Zhai, L. Jiang, Small 2012, 8, 838-84224.

[73] Y. Jiang, N. Liu, W. Guo, F. Xia, L.Jiang, J. Am. Chem. Soc. 2012, 134, 15395-15401.

[74] J. Andréasson, U. Pischel, S. D. Straight, T. A. Moore, A. L. Moore, D. Gust, J. Am. Chem. Soc. 2011, 133, 11641-11648.

[75] M. Ali, P. Ramirez, H. Q. Nguyen, S. Nasir, J. Cervera, S. Mafe, W. Ensinger, ACS Nano 2012, 6, 3631-3640.

[76] P. Ramirez, M. Ali, W. Ensinger, S. Mafe, Appl. Phys. Lett. 2012, 101, 133108.

[77] K. Tybrandt, R. Forchheimer, M. Berggren, Nat. Commun. 2012, 3, 871.

[78] K. Tybrandt, E. O. Gabrielsson, M. Berggren, J. Am. Chem. Soc. 2011, 133, 1014110145.

[79] M. Ayuba, A. Ivanova, E. Instulia, M. Cecchinia, G. Chansina, C. McGilvery, J. Honga, G. Baldwind, D. McCombc, J. B. Edela, T. Albrecht, Electrochim. Acta 2010, 55, 8237-8243.

[80] Y. He, D. Gillespie, D. Boda, I. Vlassiouk, R. S. Eisenberg, Z. S. Siwy, J. Am. Chem. Soc. 2009, 131, 5194-5202. 
[81] S. Majd, E. C. Yusko, Y. N. Billeh, M. X. Macrae, J. Yang, M. Mayer, Curr. Opin. Biotechnol. 2010, 21, 439-476.

[82] C. Dekker, Nat. Nanotech. 2007, 2, 209 - 215.

[83] S.Wu, F.Wildhaber, A. Bertsch, J. Brugger, P. Renaud, Appl. Phys. Lett. 2013, 102, 213108.

[84] M. Queralt-Martín, E. García-Giménez, V. M. Aguilella, P. Ramirez, S. Mafe, A. Alcaraz, Appl. Phys. Lett. 2013, 103, 043707.

[85] D. Momotenko, H. H. Girault, J. Am. Chem. Soc. 2011, 133, 14496-14499.

[86] P. Ramirez, V. Gómez, M. Ali, W. Ensinger, S. Mafe, Electrochem. Comm. 2013, 31, 137-140.

[87] X. Duan, T.-M. Fu, J. Liu, C. M. Lieber, Nano Today 2013, 8, 351-373. 


\section{Table 1}

Chemical (solution properties), thermal (temperature), electrical (voltage and gate potential), and optical (UV light) inputs modulating the nanopore conductance and ionic selectivity (outputs).

\section{Figure 1}

The polyprotic acid chains functionalized on the conical pore surface allow a multilevel response in the $I-V$ curve that can be tuned by the solution $p H$ (numbers in the $I-V$ curves). ${ }^{[37]}$ The $p H$ dependence obtained for $V<0$ is reversed with respect to the case $V>0$ because of the electrical rectification of the conical nanopore. The low (logic " 0 ") and high (logic "1") $p H$ values are the inputs and the respective low and high conductance values are the outputs of the logic function AND. The intermediate $p H$ value allows for multivalued logic functions. The electrolyte concentration is $c_{0}=0.1 \mathrm{M}$ and the conical pore radii are $100 \mathrm{~nm}$ and $10 \mathrm{~nm}$ approximately.

\section{Figure 2}

Scheme of the enabled OR (EnOR) function operated with two nanopores connected in series between two electrodes. The nanopore (1) has thermally-responsive chains ${ }^{[44-47,57]}$, while the nanopore (2) contain carboxylic acid chains. ${ }^{[34]}$ The three input values $i_{\mathrm{k}}(\mathrm{k}=1,2$, and 3$)$ are the temperature, $p H$, and voltage, as shown in the table. The output is the total current $I$ across the three-compartment cell. The low $(O f f)$ and high $(O n)$ conductance $\left(G_{i}\right)$ states of the two nanopores are also included in the table. 


\section{Figure 3}

The experimental $I-V$ curves obtained for cigar-shaped nanopores with lysine chains at $c_{0}=$ $0.1 \mathrm{M} \mathrm{KCl}$. The FESEM image shows the fracture of a pore with opening diameters in the $100 \mathrm{~nm}$ range. ${ }^{[75]}$ Symmetric (low, intermediate, and high $\mathrm{pH}$ ) and asymmetric (isoelectric point $p I=5)|\operatorname{acidic}(p H=2.5), p I| \operatorname{basic}(p H=10.5)$, and basic|acidic $)$ configurations are considered. ${ }^{[76]}$ The cartoons illustrate the distribution of fixed charges in the pore tips and the input assignments are indicated in the axis. Note that the logic functions $X O R, I N H-1$, and INH-2 are obtained with a single multifunctional pore. 


\begin{tabular}{|ll|}
\hline INPUT & REFERENCES \\
\hline Chemical & \\
& \\
$p H$ and carboxylic groups & $1,32,34,70$ \\
$p H$ and amino groups & 15 \\
$p H$ and amino/carboxylic groups in bipolar diode & 42 \\
$p H$ and amino/carboxylic groups in bipolar transistor & 33 \\
$p H$ and amphoteric groups & 16,75 \\
$p H$ and phosphonic groups & 37 \\
$p H$-sensitive polymer brushes & 45 \\
Ca ${ }^{2+}$ and carboxylic groups & 38,80 \\
$p H$ and DNA chains & $17,36,70$ \\
$\mathrm{~K}^{+}$and DNA chains & 39 \\
$\mathrm{H}_{2} \mathrm{O}_{2}$ and protein receptor & 25 \\
protein adsorption on specific receptors & $19,23,30$ \\
\hline Thermal & \\
& \\
temperature-sensitive polymer brushes & 44,70 \\
temperature and $p H$-sensitive polymer brushes & 46,47 \\
\hline Electrical & \\
gate potential and field effect nanopore & $21,22,41,43,66,67,70$ \\
\hline Optical & \\
UV light and photolabile groups & $48,68,69,71,72$ \\
\hline
\end{tabular}

Table 1 
Functionalisation of the nanopore with polyprotic acid groups
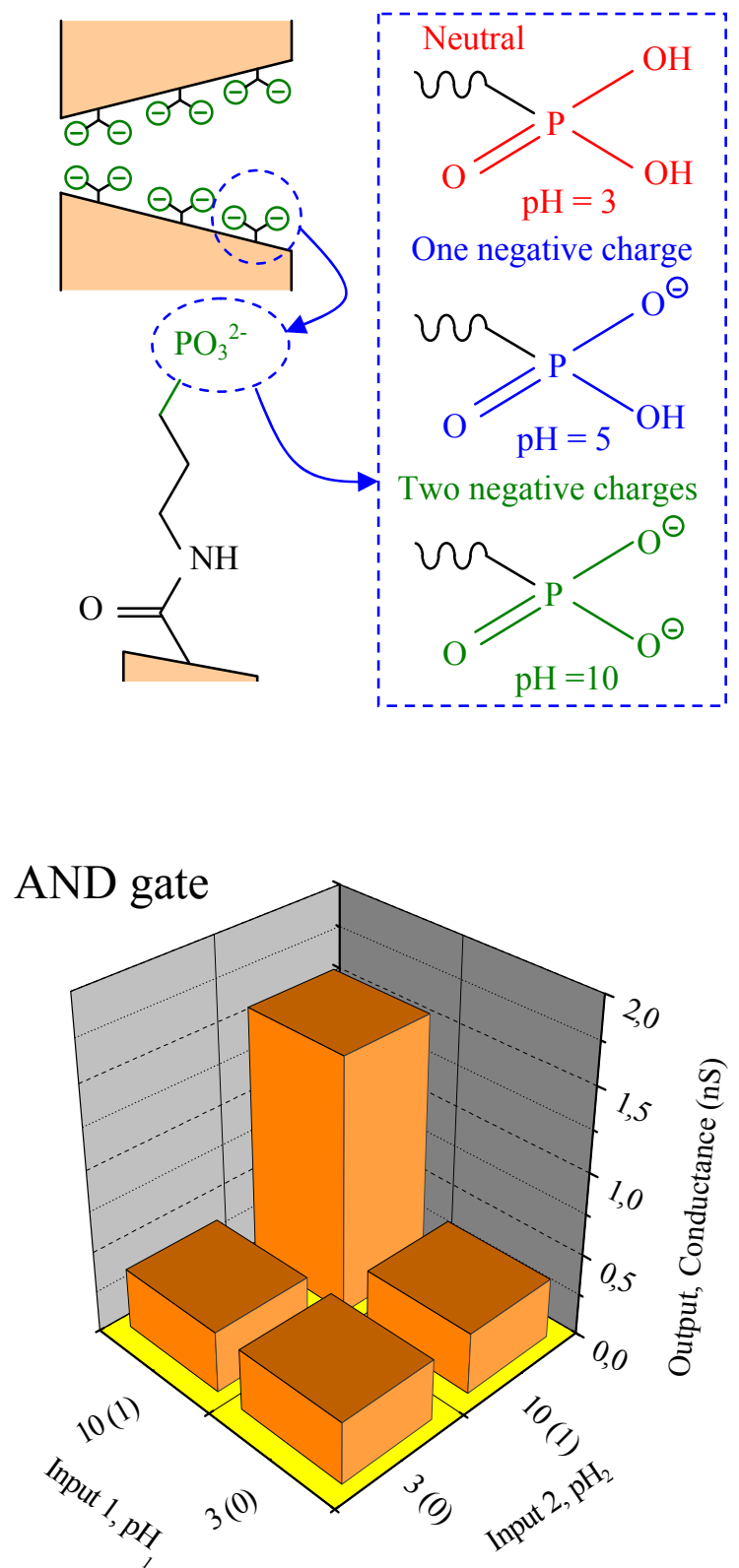

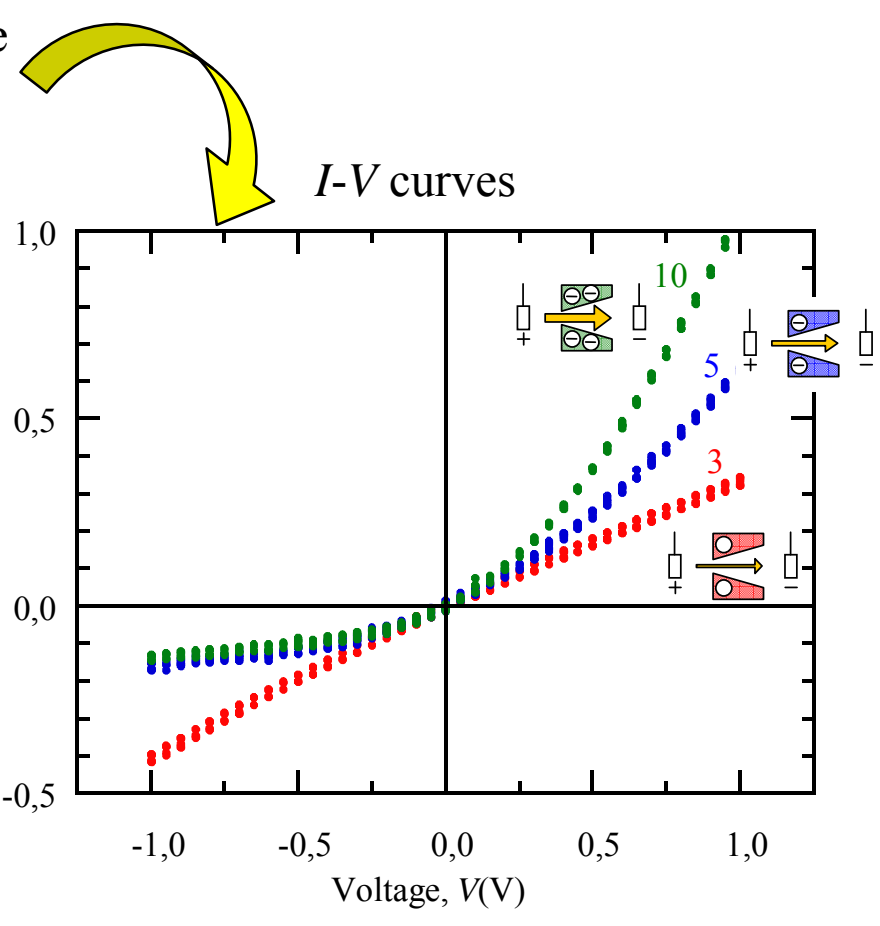

Multivalued logic gate

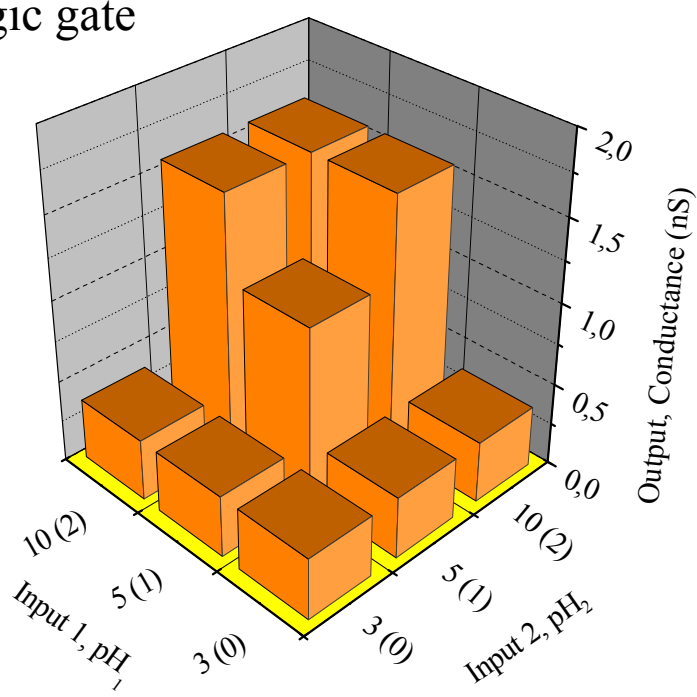

Figure 1 
As-fabricated pores with bullet-like tips functionalized with carboxylic groups
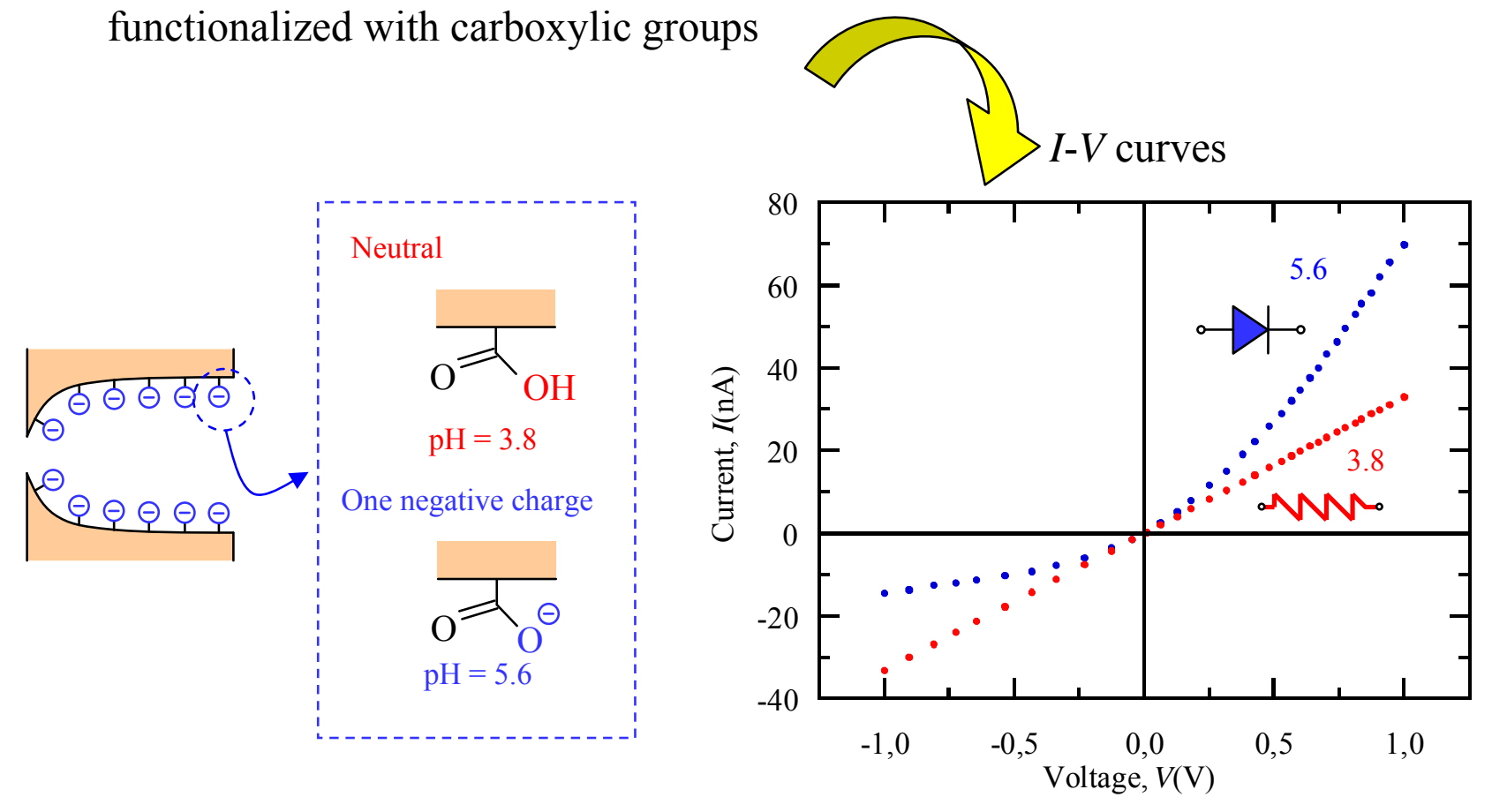

Logic network in three-compartment electrochemical cell

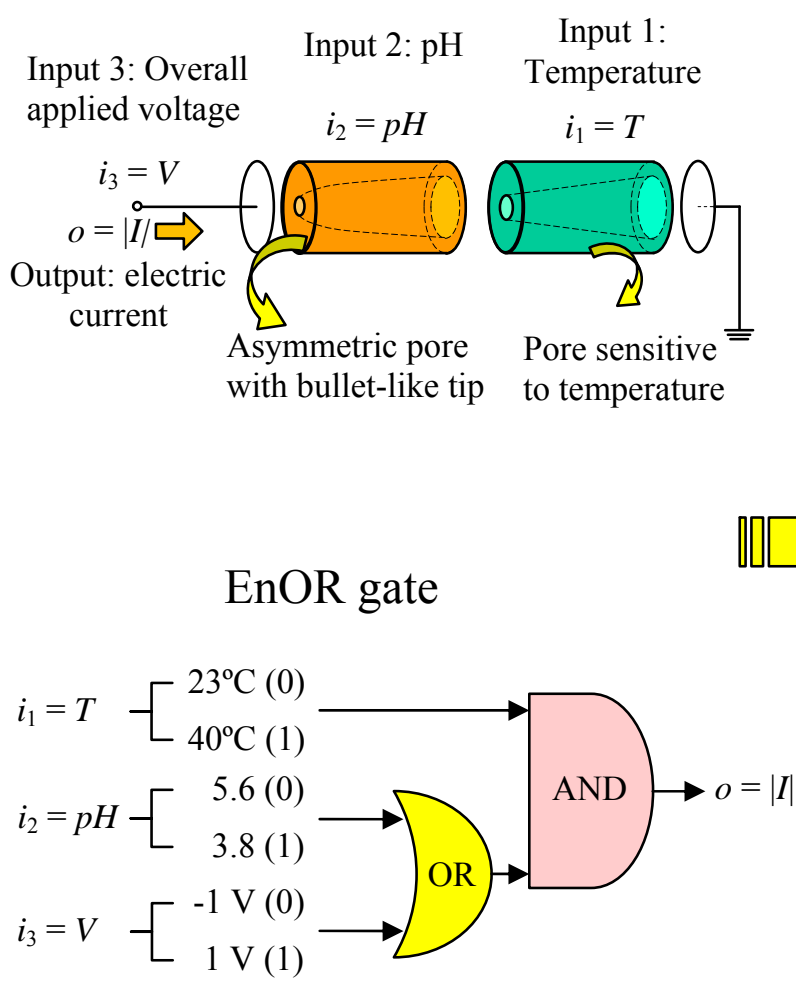

Truth Table

Asymmetric pore Pore sensitive to temperature

\begin{tabular}{|c|c|c|c|c|c|c|}
\hline$i_{1}$ & $G_{1}$ & $i_{2}$ & $i_{3}$ & $G_{2}$ & $|I|(\mathrm{nA})$ & $O$ \\
\hline 0 & Off & 0 & 0 & Off & 9.47 & 0 \\
\hline 0 & Off & 1 & 0 & On & 11.5 & 0 \\
\hline 0 & Off & 0 & 1 & On & 12.8 & 0 \\
\hline 0 & Off & 1 & 1 & On & 11.5 & 0 \\
\hline 1 & On & 0 & 0 & Off & 12.7 & 0 \\
\hline 1 & On & 1 & 0 & On & 23.1 & 1 \\
\hline 1 & On & 0 & 1 & On & 32.7 & 1 \\
\hline 1 & On & 1 & 1 & On & 23.1 & 1 \\
\hline
\end{tabular}

Figure 2 
Cigar-shaped pores functionalized with amphoteric groups
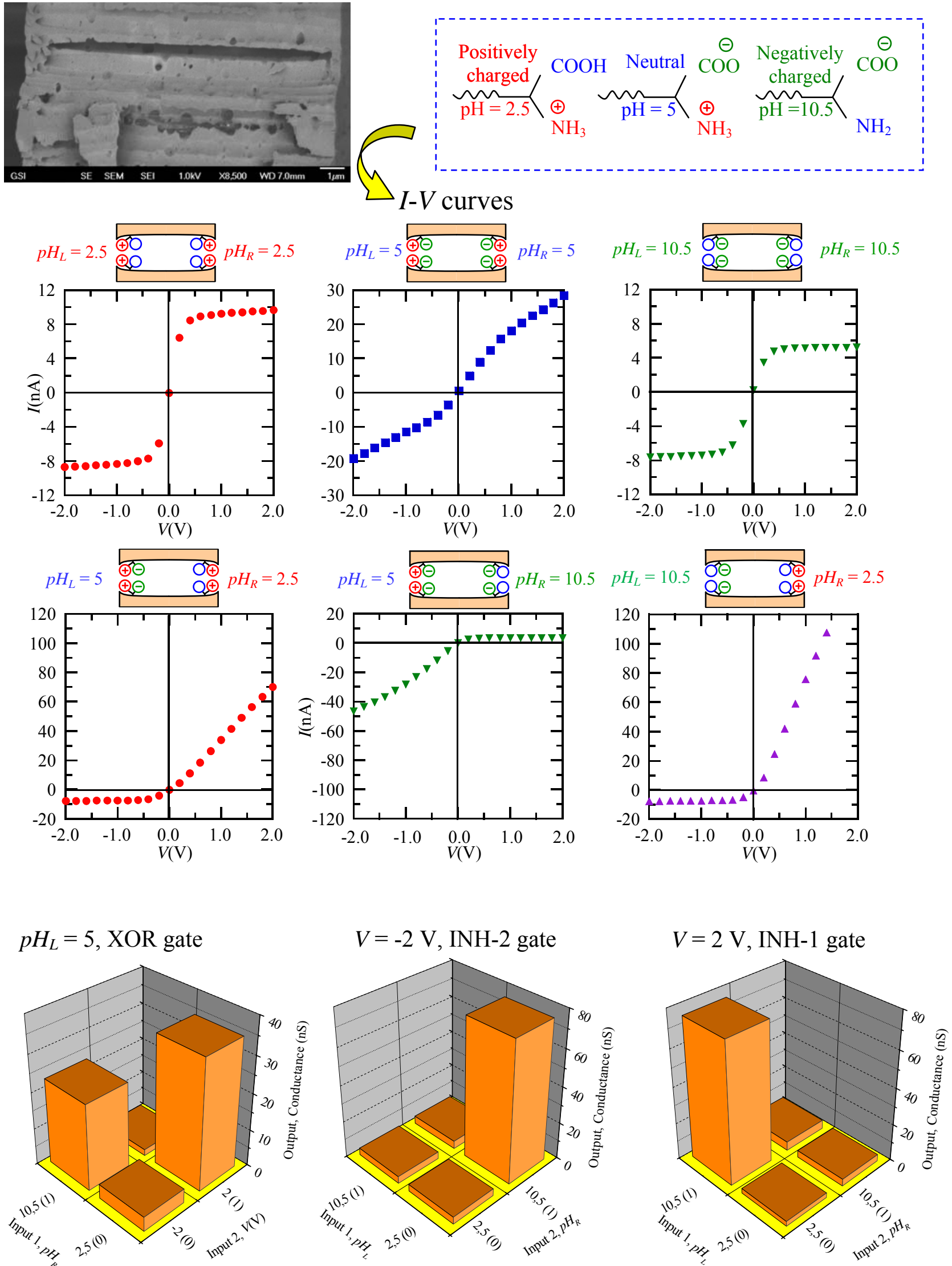

Figure 3 